A VALUE PLATFORM ANALYSIS PERSPECTIVE ON CUSTOMER ACCESS INFORMATION TECHNOLOGY

\author{
Robert J. Kauffman \\ Laura Lally
}

Replaces: Working Paper IS-93-5

Working Paper series

STERN IS-93-22 


\title{
A VALUE PLATFORM ANALYSIS PERSPECTIVE ON CUSTOMER ACCESS INFORMATION TECHNOLOGY
}

September 15, 1993

\author{
ROBERT J. KAUFFMAN \\ Associate Professor of Information Systems \\ Stern School of Business \\ New York University \\ LAURA LALLY \\ Assistant Professor of Business Computer Information Systems \\ School of Business \\ Hofstra University
}

The authors wish to thank Joseph S. Pendleton III, Lisa Gresh, and Orest Borys at Meridian Bancorp for providing access to their electronic banking operations. At New York University, Avijit Ghosh, Tomas Isakowitz, Hank Lucas, and Bruce Weber provided helpful comments on an earlier version of this paper. 


\title{
A VALUE PLATFORM ANALYSIS PERSPECTIVE ON CUSTOMER ACCESS INFORMATION TECHNOLOGY
}

\author{
September 15, 1993
}

\begin{abstract}
Customer access information technologies (CAITs) provide a link between a firm and its customers. Firms invest in CAITs to reduce costs, increase revenues and market share, lock in existing customers and capture new ones. These benefits, however, are notoriously difficult to measure. This paper proposes an evaluative method for CAIT deployment called value platform analysis, that is based on a conceptual model drawn from the theory of retail outlet deployment in marketing science. The model focuses on the impact of CAIT features and environmental features on transactions generated by the CAIT. Specific econometric models are developed for deployment. Hypotheses regarding the likely impact of automated teller machine (ATM) location design choices and environmental features on ATM transactions are evaluated. The results indicate that there are a number of key features influencing ATM performance. Two distinct ATM deployment scenarios emerge: one for servicing a bank's own customers, and another for providing transaction services for customers for a fee.
\end{abstract}

KEYWORDS: $\quad$ Automated teller machines, customer access information technology, electronic banking, information technology, IT deployment, IT value, systems design, value platform analysis. 


\section{INTRODUCTION}

\subsection{CAIT: Definition, Problem Statement and Analytic Approach}

Information technology (IT) can link organizations with their customers in a competitive environment. Through the use of devices such as point-of-sale terminals, order entry terminals and automatic teller machines (ATMs), customers have a direct channel to perform transactions without human intermediaries. By offering this access to customers, organizations hope to maintain their competitiveness. The IT cost of these systems is typically high, requiring investments in customer terminals, telecommunications hardware and software, and hardware and software to process the transactions.

Implementing these systems may require substantial changes in the organization's information architecture and the fundamental processes by which it conducts its business. Customers must be educated about using the system, paper transaction trails are often replaced with electronic ones, and the order taking staff may be downsized or eliminated entirely $[4,17,29]$. These changes increase the lead time for implementation and increase the stake organizations have in the system's success.

Deployment of systems that are not adopted and used by a critical mass of the organization's customers can result in large losses. For example, Chemical Bank had to write off millions of dollars because of the failure of its home banking system, Pronto [11]. Yet, success stories such as American Airlines' SABRE system [26] and McKesson Drug's Economost system [4] indicate that direct links to customers can result in large increases in revenue and market share. When considering an investment in such technologies, therefore, managers need guidance in crafting systems that will be used by customers and benefit the organization. This study addresses their concerns by:

(1) providing a theory-based conceptual model for the deployment of computer and communication-based technologies that provide a direct link between organizations and their customers -- customer access information technology (CAIT), and, 
(2) developing an evaluative approach called value platform analysis that can be used by management to determine whether appropriate environmental conditions exist to deploy CAIT, and to provide guidelines for choosing the CAIT's features, its value platform, that will have the greatest leverage on the CAIT's success; and,

(3) applying the CAIT model and value platform perspective in the context of a large commercial bank's ATM deployment.

The model we propose is drawn from marketing science and adapted to CAIT with insights drawn from the strategic IT literature.

\subsection{CAIT: Benefits Recognized by the Strategic IT Literature}

The strategic IT literature notes the potential benefits of CAIT, and offers frameworks and guidelines for identifying systems with the potential for generating competitive advantages. Yet, the literature also notes a lack of measures for evaluating the benefits of these systems and controlling the risk involved in making such expensive investments $[5,14,16]$. There are a number of potential benefits for the organization that deploys CAIT $[12,14,17]$ :

(1) Direct customer access can lower transaction costs by increasing transmission speeds, reducing costly paperwork and eliminating human intermediaries.

(2) Direct access can provide a means of product differentiation by furnishing additional services to the customer, such as an ability to:

* check account status without human intermediaries;

* offer a wider range of times and locations for performing transactions, and a wider variety of payment options; and,

* reduce inventory carrying costs due to the efficiency with which new goods can be ordered.

CAIT features such as touch screens, optical scanning devices and icon-driven interfaces make the terminals easier for the customer to use, further enhancing product differentiation. Offering a superior product or service can increase revenue.

(3) Direct access systems can lock in the organization's existing customer base by increasing switching costs. McFarlan suggests that when an organization's customers have "adopted a series of increasingly complex and useful procedures that insinuate themselves into the customer's routine ... the customer will have to spend too much time and money to change suppliers" [25]. 
(4) Direct access systems allow the organization to expand its customer base by establishing points of electronic presence in new areas.

\subsection{Frameworks and Guidelines for CAIT Evaluation}

Several conceptual frameworks have been suggested in the literature to guide managers contemplating an investment in CAIT. Reich and Benbasat [28] propose a model that identifies the factors influencing the development, adoption, and resulting competitive advantage of "customer-oriented strategic systems." Vepsalainen and Apte [34] draw on transaction cost theory to identify the types of customer transactions best suited for automated delivery channels in the financial services sector. They propose that transactions which are fixed in nature, do not require customization, and are quickly completed (rather than those requiring continuous attention), are best suited for automation. Thompson and Mead [31] identify alternative power relationships between buyers and sellers, and provide guidelines for using customer access information technology to increase the power of deploying organizations over their customers.

These frameworks can provide insights for the manager contemplating the development of a CAIT in terms of:

(1) whether it is suitable for a particular type of customer access;

(2) which of its features are likely to enhance an organization's ability to lock in customers; and,

(3) whether the organizational and industrial factors conducive to successful development and adoption are present.

What these frameworks do not provide is a way of measuring the degree to which business value has been realized, once the CAIT has been developed, and the impact that environmental factors may have had on the creation of business value.

CAIT managers, therefore, need a conceptual model that:

(1) enumerates the factors applicable to deploying a CAIT;

(2) organizes the factors into meaningful groups; and,

(3) predicts the impact of these factors on measures of business value. 
This study will first develop a CAIT deployment model that is motivated by retail deployment theory, and will apply it in the context of a new analytical perspective that we call value platform analysis. The methodology involves specifying propositions that can be drawn from this model, indicating the likely impact of key actions on the ability of CAIT deployment sites to meet their objectives. The model also distinguishes immediately feasible actions from eventually feasible actions. From this conceptual model, and the specifics of a given CAIT deployment problem, managers can generate and test hypotheses regarding the impact of particular key actions on the success of a CAIT deployment strategy and determine which strategies are immediately versus eventually feasible. The CAIT deployment model will be applied to conduct a value platform analysis for ATM deployment. The results of the study:

(1) indicate how appropriate the CAIT model is in providing insight for ATM deployment managers;

(2) provide specific advice to the bank's managers regarding their ATM deployment strategy; and,

(3) suggest that value platform analysis can be used by other CAIT managers in evaluating their deployment strategies.

\section{A CONCEPTUAL MODEL OF CAIT DEPLOYMENT}

Identifying the key features in CAIT deployment was the first step. This study chose retailing as its referent discipline and as the source of potential key features.

Retail deployment and CAIT deployment share a number of common features. The success of each depends upon creating a market presence by establishing deployment sites across heterogeneous environments apart from organizational headquarters. The success of both retail sites and CAIT sites depends upon their ability to generate customer transactions. Examining the theoretical literature regarding the placement of retail outlets, therefore, can provide insight into CAIT deployment. 


\subsection{Key Issues in Retail Deployment}

Retail deployment strategy addresses two questions: "What do I offer?" and "Where do I place it?"

"What do I offer?" Determining the answer to this question involves the choice of features considered to be controllable by the retail manager and focuses on the features of the retail outlet for the product or service $[3,9,23]$. These features will be referred to as the value platform, consisting of the merchandise assortment, atmosphere, service, convenience of the outlet, and price of the goods and services for sale [9]. Value platform variables focus on the nature and attractiveness of the products or services, the means by which the customer is encouraged to consume or use them, and the characteristics of the immediate site that make them accessible to the customer. Locational convenience, low prices, a large assortment of merchandise, good customer service, and high merchandise quality are considered important attributes by customers in many types of retail outlets [32]. In competitive environments, retail firms strive for recognition, continually re-evaluating value platform features [6]. Investing in value platform features, therefore, represents immediate (though often expensive) actions that can differentiate the product or service, and increase transactions and market share within the current environment and with the firm's existing customer base.

"Where do I place it?" This question deals with the environment into which the outlet is placed and is considered to be "probably the single most important factor in retail profitability" $[9$, p. 15]. Features of a given environment are considered to be non-controllable by retail managers $[3,9,24]$. Location strategy involves choosing from among differing fixed environments when placing outlets or determining which existing outlets to remove. The goal is to identify the environments for outlets that are most conducive to transaction generation and market share. With an outlet in place in a given environment, the manager does not have the option of fine tuning the environmental features, as is possible with the value platform features. Only the option of relocating the outlets to different environments remains.

The most crucial non-controllable environmental factor is the customer. 
According to Rachman, "the retail firm can do little to make the consumer conform to its wishes and desires" [27]. Because retailers cannot manipulate customer characteristics, retail firms must identify groups of people with features that make them likely customers and locate their outlets to reach these customers. Studies have shown that environmental features such as population density, age, income and education level can have a significant impact on sales $[13,22,27]$. Other environmental features are viewed as constraints on the ability of a firm to interact with its desired customers. The major constraint on the success of a retail outlet in capturing customers is usually believed to be competition in the environment $[3,8,24]$. The greater the number of alternatives to the outlet, the less the likelihood that a customer will patronize that outlet [9]. Other environmental constraints include the economic, legal, and social conditions within an outlet's environment.

Marketing theory views value platform and location strategy features as inputs to a sales function that generates customer transactions and results in revenues and market share [19]. Drawing on these concepts and using terminology from Ghosh and McLafferty [9], we have developed the Retail Outlet Deployment Model, as shown in Figure 1.

Figure 1. The Retail Outlet Deployment Model

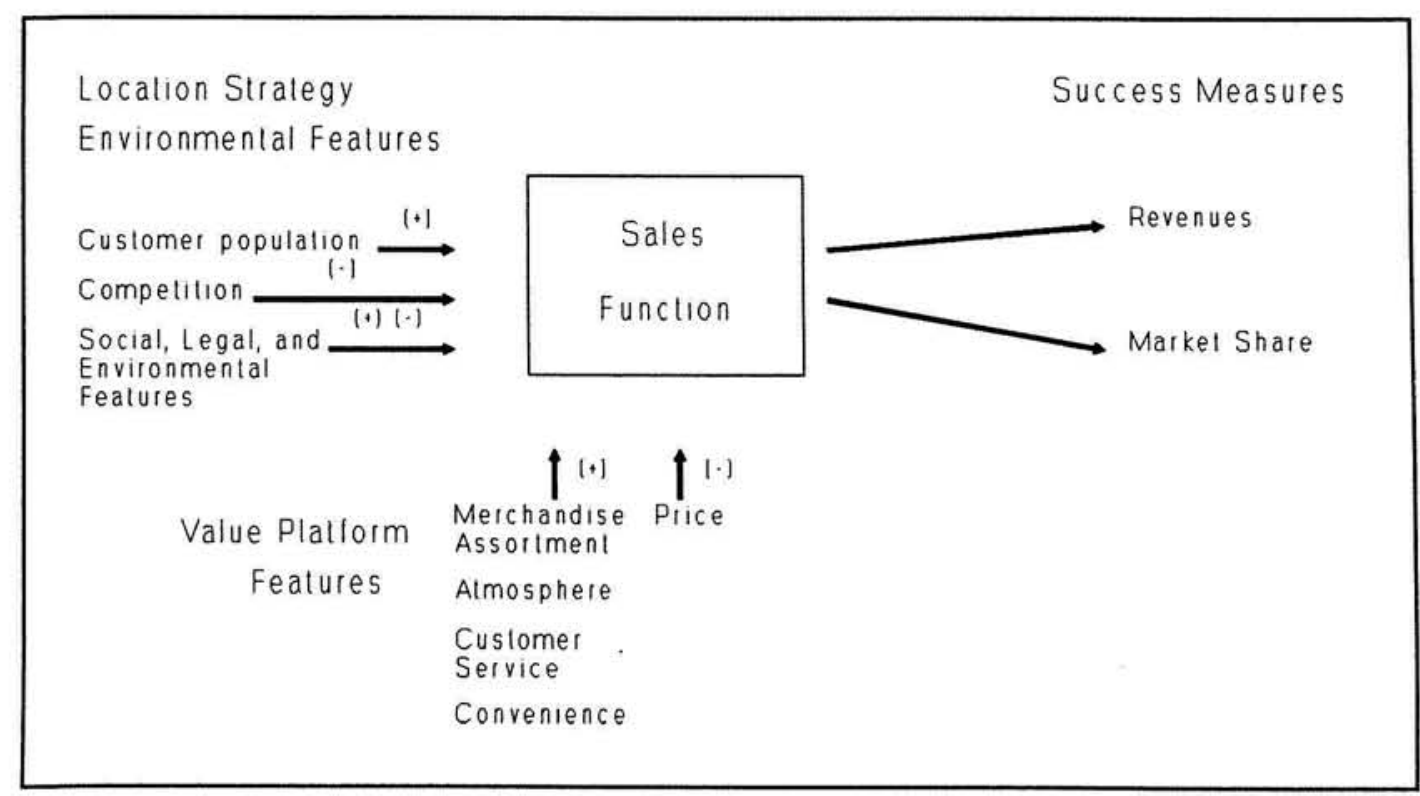


From this perspective, we have developed the concept of value platform analysis -- evaluating potential value platform features in terms of their ability to produce value for a firm, given the constraints of the deployment environment. Value platform analysis is applied next to CAIT deployment.

\subsection{The Customer Access Information Technology Model}

CAIT deployment managers need to consider which CAIT features will make the sites most attractive to customers. When determining "What do I offer?" CAIT managers must choose features from a number of alternatives promoted by vendors as being likely to increase customer transactions. They must also determine if these features are worth their cost. Like the retail outlet, the immediate site for the CAIT terminal must be chosen so that it is convenient to the customer. Customer support services may be necessary to assure adoption, and the manager must decide whether to charge customers a fee for use.

CAITs are typically deployed across a number of different geographical areas with varying customer demographics and degrees of competition. When determining "Where do I place it?" CAIT deployment managers must consider the characteristics of customers that impact where they decide to conduct transactions. The presence of a competitor's CAIT can also impact the likelihood of conducting transactions.

By adopting a value platform analysis perspective, CAIT managers can formulate better deployment strategies. The retailing model identifies the key decisions in deployment, suggests their likely impact on use, organizes them into meaningful groups of controllable and non-controllable features, and distinguishes between the resulting immediately feasible and eventually feasible actions. Adapting a value platform analysis perspective to CAIT deployment involves treating each CAIT deployment site as a retail outlet and applying the value platform and location strategy concepts to the "What?" and "Where?" questions faced when crafting a value platform strategy most appropriate to the deployment environment. Additionally, business value measures unique to the specific CAIT being deployed must be identified.

Value Platform Features. The value platform for a CAIT consists of the 
services delivered by the CAIT and the features of its immediate deployment site. Applying the merchandise assortment concept to CAIT yields two variables for consideration: the number of services provided by the CAIT and the technical quality of these services. A manager deploying a CAIT must choose among optional features offering different degrees of service and alternative technological infrastructures, which can affect the speed and reliability with which the services are performed. The retail model suggests that an increase in any of these features will have a positive impact on transactions generated. Providing user support in a CAIT environment is analogous to offering customer service to customers while they shop. The retail model suggests that an increase in user support, for example, the installation of customer hotlines, also will have a positive impact on transactions.

Convenience to the customer depends upon accessibility, which describes the geographic convenience of a CAIT, and availability, which addresses the time frame during which CAIT services can be used. Accessibility and availability are treated separately here because they represent two distinct features of CAIT, which may be determined and manipulated separately. The retail model suggests that improvements in either will have a positive impact on customer transaction volumes.

The retail model also suggests that an increase in price or customer usage fees for the CAIT, as in retail deployment, generally will have a negative impact on transactions generated. In situations where there is no explicit price charged to the customer, the analyst should consider whether the services offered carry implicit prices. This is very often the case for customer access information systems. For example, service providers encourage customers to dial into electronic mail services at off-peak hours by allowing system response time to degrade when peak loads are reached.

Location Strategy and Environmental Variables. For CAIT these features describe the environments into which the technology is deployed. A base of potential users is key to the generation of transactions at a CAIT deployment site, while competition is viewed as a having a negative impact on transactions.

Business Value Measures. Transactions, in turn, generate business value in 
a number of ways: by increasing revenue, decreasing costs and improving market share. Recent research, reviewed by Banker, Kauffman, and Mahmood [2], suggests that there are many kinds of measurement strategies to detect business value that is derived from IT investments. Some of the evaluation methods are highly qualitative while others rely on quantitative analysis. Whatever the evaluation method applied to examine the business value impacts of CAIT, the analyst should be aware that the idea here is to capture the relevant dimensions of value, based on the stakeholders affected by the investment.

Figure 2 summarizes the major components of the CAIT deployment model.

Figure 2. The Customer Access Information Technology Deployment Model

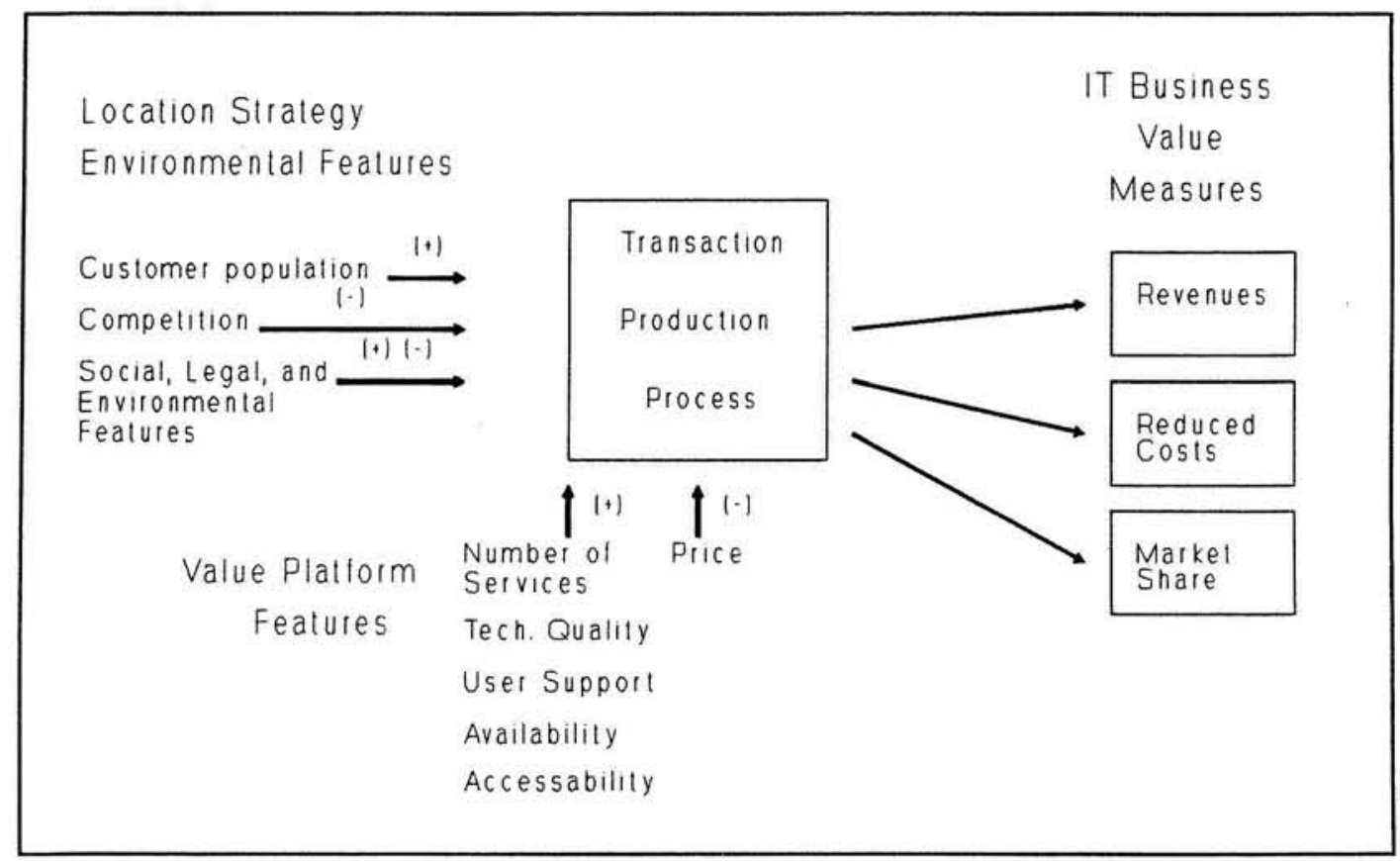

From this model, the following propositions can be drawn regarding the impact of value platform and environmental features on transaction generation: number of transactions generated. 


\section{Customer}

Proposition: An increase in the number of customers in a CAIT's environment will lead to an increase in the number of transactions generated.

\section{Competitor}

Proposition: $\quad$ An increase in the number of competitors in a CAIT's environment will lead to a decrease in the number of transactions generated.

\section{DEPLOYMENT EVALUATION: MODELING ISSUES AND HYPOTHESES}

ATMs, originally deployed by banks to gain a competitive edge over non-ATM deploying banks $[10,20]$, are one of the mostly highly publicized examples of CAIT. Competitors responded swiftly to the use of ATMs by industry leaders [21,33]. As a result, ATM services have become a "strategic necessity," which a bank must provide to remain competitive $[5,30]$. Increasingly, the ATMs of different banks are linked into networks, while networks, in turn, are merging to provide wider accessibility to customers and to reduce costs.

\subsection{Modelling Deployment: Preliminary Analysis}

Banks plan an ATM strategy with the goal of maximizing the business value their ATMs can generate, subject to the costs of providing ATM service. This business value margin depends upon the type of ATM service being delivered and the cost structure of the financial institution providing the service.

Two Types of ATM Services. Customer service involves transactions performed by the bank's own customers. In the absence of explicit fees, ATMdelivered customer services create business value indirectly, through the incomegenerating collateral services the bank provides for the customers whose accounts it holds. Interchange involves transactions performed for the customers of other banks. They create business value directly, through fees received from other banks for processing their customers' transactions.

Service Production Costs and Institution Size. Large commercial banks have the resources to establish their own ATM services and a large enough customer base to absorb the fixed costs of mainframe and ATM software and machines, and 
communication lines. With a base of connected ATMs in place, large banks can process transactions at a variable cost that is lower than the interchange fee charged by banks performing transactions for other banks' customers. This cost structure leads large institutions to prefer processing their own customers' transactions. Large institutions can further leverage their investment by performing transactions for other banks' customers as well, earning revenues from interchange fees that are in excess of the variable costs of providing the service. Large institutions, therefore, are more likely to follow a customer service and interchange strategy -- pursuing the transactions of customers of competing banks, as well as those of their own customers.

In contrast, small institutions have few resources to devote to establishing ATM service and few customers to absorb the fixed costs. These institutions are more likely to focus on a customer service only strategy -- providing just the level of ATM services necessary to retain their own customers. Small banks may provide only a few proprietary ATMs at their branches. Credit unions may not provide any of their own ATMs at all. Instead, by linking into an existing ATM network, these institutions can provide the service required by their customers. Paying higher variable costs in the form of interchange fees to other banks is less expensive for them than the combined fixed and variable costs of providing the service themselves.

Electronic Banking Strategy at Meridian Bancorp. Our site for this research, Meridian Bancorp, is one of the largest commercial banks in Pennsylvania, operating branches throughout the southeastern quarter of the state. As a large commercial bank, Meridian chose the customer service and interchange strategy, aggressively pursuing an ATM deployment strategy to capture the transactions of both its own customers and those of competing banks.

Managers contemplating a customer service and interchange strategy face three types of decisions:

(1) They must choose the regions in which they wish to compete for transactions. These regions are referred to by the bank as their retail service clusters (RSCs). 
(2) They must consider the existing configuration of ATMs in these RSCs and configure their own ATMs to make them locationally desirable to both their own customers and customers of other banks.

(3) They must choose ATM features that will enhance the attractiveness of their ATMs.

\subsection{A CAIT Value Platform Analysis for Electronic Banking Services: Formal Model and Hypotheses}

Stated in terms of our CAIT model, we propose that transactions are generated as a function of environmental and value platform variables. The influence of the RSC environment is a function of customers and competitors that operate within it, and the attributes within the RSC of the electronic banking value platform. We distinguish the local level aggregate from the regional level because value platform service features are attractive to customers who need to do business with the bank at various locations within a geographic area.

Formal Model Concepts. More formally, we can represent this in terms of three separate functions, a transaction production function, an environmental influence function, and a value platform function:

$$
\begin{array}{ll}
\text { TRANSACTIONS }_{n z} & =f(E \text { ENVIRONMENT } \\
\text { ENVIRONMENT }_{z} & =g\left(\text { VALUE_PLATTOMER_DEMOGRAPHICS }_{z}, \text { COMPETITORS }_{z}\right) \\
\text { VALUE_PLATFORM }_{n z} & =h\left(\text { ATTRIBUTE }_{1 n z}, \ldots, \text { ATTRIBUTE }_{k n z}\right)
\end{array}
$$

where

TRANSACTIONS $_{n z} \quad=$ number of transactions performed at ATM $n$ in RSC z;

ENVIRONMENT $\quad$ = environmental features relevant to transaction production in RSC z;

VALUE_PLATFORM $_{n z} \quad$ = the value platform design selected by the bank for ATM $n$ in RSC z;

CUSTOMER

DEMOGRAP HICS $_{z} \quad=$ ATM-relevant customer demographics in RSC z;

COMPETITORS $_{z} \quad$ = firms that compete for ATM transactions in the RSC; 

ATTRIBUTE knz $_{\text {a }}=$ ATM service attribute $k$ that management selects to configure the value platform of ATM $n$ in RSC $z$.

Three Transaction Types. Three types of transactions are considered in pursuing a customer service and interchange strategy. Each transaction type draws upon a different set of environmental features in the bank's retail service clusters $(z=1, \ldots, Z)$ and the value platform features of each of its ATMs $(n=1, \ldots, N)$ within an RSC.

US_ON_US Transactions (UOU). These are customer service transactions performed by the bank's customers at the bank's own ATMs. US_ON_US transactions are generated by the bank's ATMs as a function of the features of the environment in which the ATM is placed, and the features that make the ATM attractive to the bank's customers. US_ON_US transactions tend to take place at branch site, full function ATMs. (Full function ATMs perform deposits and transfers, as well as withdrawals and balance inquiries). US_ON_US transactions create business value by providing the customer services necessary to retain accounts.

US_ON_OTHERS Transactions (UOO). These are customer service transactions conducted by the bank's customers on competing banks' ATMs. US_ON_OTHERS transactions usually consist of cash withdrawals, transfers and balance inquiries (rather than bill payments or deposits, which are more often done as US_ON_US transactions). These transactions provide a lower business value margin than US_ON_US transactions, because the value created is reduced by the cost of the interchange fee that must be paid to the bank owning the ATM.

From a strategic standpoint, two types of US_ON_OTHERS transactions can be distinguished: US_ON_OTHERS transactions that take place within the bank's core operating area, the RSCs where the bank operates its own branches and ATMs, and US_ON_OTHERS transactions that take place outside the core operating area.

US_ON_OTHERS transactions within the bank's core operating region are generated at competing banks' ATMs as a function of the features of the environment in which the ATMs are placed, and the configuration and attractiveness features of the bank's own ATMs in the same RSC environment. The value platform analysis 
perspective suggests that by making its own ATMs more attractive, a bank makes it less likely that its customers will use the nearby ATMs of competing banks [9]. The goal of ATM deployment strategy, therefore, is to place the bank's ATMs within each RSC in a manner that will attract the bank's customers to its own ATMs and reduce the likelihood that US_ON_OTHERS transactions will occur at nearby competing banks' ATMs.

Supporting US_ON_OTHERS transactions outside the core operating area, in regions that the bank does not cover within the state or out of state, for example, is considered a necessary part of a full customer service strategy. Since deploying its own ATMs in these regions would be prohibitively expensive, the bank permits customers and competing banks to skim off the greatest share of business value from these remotely conducted transactions. Once operating regions have been chosen, US_ON_OTHERS transactions outside the core area are not considered when planning an ATM deployment strategy. Instead, paying interchange fees to the banks that service the customers is a necessary cost of doing business.

OTHERS_ON_US Transactions (OOU). The third transaction type is strictly fee-generating cash dispensing and balance inquiry services that the bank performs for the customers of competing banks. OTHERS_ON_US transactions are generated at the bank's ATMs as a function of the features of the environment into which the ATMs are placed and the features of the ATMs that make them attractive to competing banks' customers. OTHERS_ON_US transactions create business value through interchange revenue, fees paid to the bank for the transactions performed, less the variable cost of performing the transactions.

A bank pursuing a customer service and interchange strategy, therefore, must consider the total business value margin from all three transaction types on a region by region basis. Our next step was to identify specific environmental and value platform features for the bank.

Environmental Features. The bank's management believed that a larger customer base would have the positive impact suggested by the CAIT deployment model on all transaction types. Since the number of customers of competing banks 
was not available, a commonly used surrogate measure of customer base, the amount of dollar deposits in the branches, was adopted for this study. (See McAndrews and Kauffman [23] for additional discussion about the use of deposit base as a proxy when another relevant variable is unobservable.) The customer base was further characterized in terms of its likelihood to use ATMs. Measures were sought that identified the high income, young adults indicated in the ATM literature and believed by the bank's management to be the customer segment most likely to use ATMs. Family size was used as a surrogate measure of the number of young adults in an area -- an inverse relationship between family size and transactions generated was expected. Per capita income was expected to have a positive impact on all three transactions types. The managers agreed that the presence of competing bank's ATMs would have a negative impact on US_ON_US and OTHERS_ON_US transactions and a positive impact on surrounding US_ON_OTHERS transactions.

Value Platform Features. The bank's ATMs were characterized by two primary descriptors: type (cash dispensers versus full function ATMs) and location (branch versus non-branch). Cash dispensers provided only withdrawals, while full function ATMs provided for deposits and transfers between accounts as well. Full function machines and branch ATMs were expected to have a positive impact on US_ON_US transaction production. Full function machines were expected to have no impact on transactions performed by customers of competing banks (OTHERS_ON_US), but non-branch machines were expected to have a positive impact. Additionally, each ATM site had a number of features that management believed enhanced its attractiveness to customers. Surrounding auto traffic and foot traffic, site accessibility, and site visibility were all believed to have a positive impact on US_ON_US and OTHERS_ON_US transactions and to help prevent US_ON_OTHERS transactions at surrounding ATMs.

The Formal Model. This analysis yielded the following models for the business value of the three transaction types, stated on an RSC by RSC basis, with adjustments for the margins that the bank can obtain for each transaction type: 


$$
\begin{aligned}
& \text { BUSINESS_VALUE_UOU }= \\
& p I\left(U S S _ { 2 } O N \_ U S _ { 1 z } \left(\left(F A M \_S I Z E_{z}, I N C_{z}, M E R \_D E P_{z}, C O M P \_A T M s_{z}\right),\right.\right.
\end{aligned}
$$

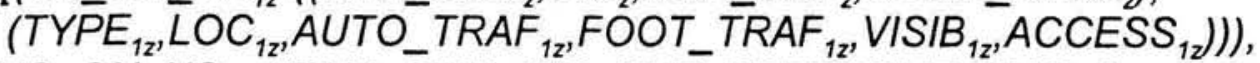

$$
\begin{aligned}
& \text { (US_ON_US }{ }_{2 z}\left(\left(F A M_{-} S I Z E_{z}, I N C_{z}, M E R \_D E P_{z}, C O M P_{2} A T M S_{z}\right)\right. \text {, }
\end{aligned}
$$

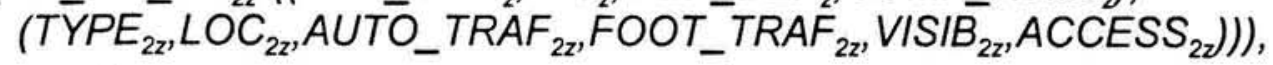

$$
\begin{aligned}
& \text { (US_ON_US } S_{n z}\left(\left(F A M \_S I Z E_{z}, I N C_{z}, M E R \_D E P_{z}, C O M P \_A T M s_{z}\right)\right. \text {, } \\
& \left.\left.\left.\left(T Y \overline{P E}_{n z}, L O C_{n z}, A U T \bar{O}_{-} T R A F_{n z}, F O O T_{-} \overline{T R A F}_{n z}, V_{I S I B_{n z}}, A^{\prime} C C E S S_{n z}\right)\right)\right)\right] \text {. }
\end{aligned}
$$

$$
\begin{aligned}
& \text { BUSINESS_VALUE_UOO }= \\
& q\left[\left(U \overline { S } _ { - } O N \_ O T H E R S _ { 1 2 } \left(\left(F A M_{-} S I Z E_{z}, I N C_{z}, M E R \_D E P_{z}, C O M P \_A T M s_{z}\right)\right.\right.\right. \text {, }
\end{aligned}
$$

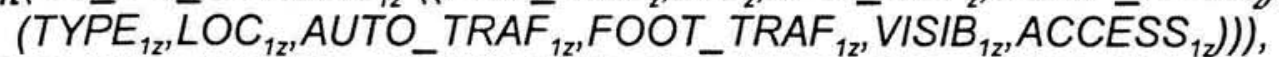

$$
\begin{aligned}
& \text { (US_ON_OTHERS }{ }_{2 z}\left(\left(\bar{F} A M \_S I Z E_{z}, I N C_{z}, M E R \_D E P_{z}, C O M P \_A T M s_{z}\right)\right. \text {, }
\end{aligned}
$$

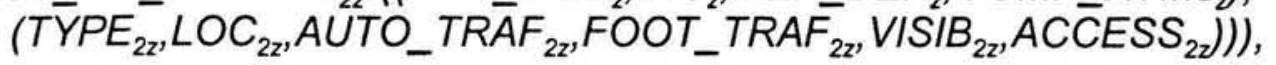

$$
\begin{aligned}
& \text { (US_ON_OTHERS }{ }_{n z}\left(\left(F A M \_S I Z E_{z}, I N C_{z}, M E R \_D E P_{2}, C O M P \_A T M s_{z}\right)\right. \text {, } \\
& \left.\left.\left.\left(T Y P E_{n z}, L^{\prime} O C_{n z}, A U T O_{-} T R A F_{n z}, F O O T_{-} T R A F_{n z}^{-}, V I S I B_{n z}, A C C E S S_{n z}\right)\right)\right)\right] \text {. } \\
& \text { BUSINESS_VALUE }= \\
& r\left[\left(O T H E R S _ { - } O \overline { N } _ { - } U _ { 1 z } \left(\left(F A M_{-} S I Z E_{z}, I N C_{z}, C O M P_{-} D E P_{z}, C O M P_{-} A T M s_{z}\right)\right.\right.\right. \text {, }
\end{aligned}
$$

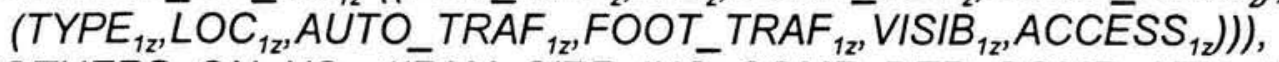

$$
\begin{aligned}
& \text { (OTHERS_ON_US }{ }_{2 z}\left(\left(\bar{F} A M \_S I Z E_{z}, I N C_{z}, C O M P \_D E P_{z}, C O M P \_A T M s_{z}\right)\right. \text {, } \\
& \left.\left(T_{Y P E_{2 z}}, \overline{L O C}_{2 z},{ }^{\prime} \text { AUTO_TRA } F_{2 z}, \text { FOOT_TRAF }_{2 z}, \text { VISIB }_{2 z}, \text { ACCESS }_{2 z}\right)\right) \text { ), } \\
& \text { (OTHERS_ON_US } \text { ( }_{n z}\left(\left(F A M_{-} S I Z E_{z}, I N C_{z}, C O M P_{-} D E P_{z}, C O M P_{-} A T M s_{z}\right)\right. \text {, } \\
& \left.\left.\left.\left(T Y P E_{n z}, \overline{L O C}_{n z}, A U T O_{-} T R A \bar{F}_{n z}, F O O T_{-} \text {TRAF } F_{n z}, \overline{V I S I B}_{n z}, A C C E \bar{S} S_{n z}\right)\right)\right)\right] \text {. }
\end{aligned}
$$

where

$$
\begin{aligned}
& \text { US_ON_US } n=\text { the number of US_ON_US transactions performed } \\
& \text { by } A T M_{n} \text { in } R S C_{z} \text {. } \\
& \text { US_ON_OTHERS } S_{n z} \quad=\text { the number of US_ON_OTHERS transactions performed } \\
& \text { on competing ATM s surrounding } A T M_{n} \text { in } R_{S S} \text {. } \\
& \text { OTHERS_ON_US }{ }_{n z}=\text { the number of OTHERS_ON_US transactions } \\
& \text { FAM_SIZE } \quad \text { = average family size in RSC z; } \\
& I N C_{z}^{-} \quad=\text { average per capita income in RSC } z \text {; } \\
& \text { MER_DEP } \quad \text { = bank's customer deposit base in RSC z; } \\
& \text { COMP_DEP } \quad \text { = competing banks' customer deposit base in RSC } z \text {; } \\
& \text { COMP_ATMs } z \quad=\text { competing bank' ATMs in RSC } z \text {; } \\
& T Y P E_{n} \\
& =\text { indicates whether ATM } n \text { is full function or cash } \\
& \text { dispensing; }
\end{aligned}
$$


$L O C_{n}$

AUTO_TRAF FOOT_TRAF ACCESS $p[\cdot], q[\cdot], r[\cdot]$
= indicates whether ATM $n$ is a branch or non-branch location;

= measures the auto traffic surrounding $A T M_{n}$.

= measures the foot traffic surrounding $A T M_{n}$.

= measures the accessibility of ATM ${ }_{n}$.

= business value margin functions for UOU, UOO and transactions, respectively.

Unit of Analysis. Our unit of analysis, the bank's ATM within its RSC environment, reflect the value platform analysis perspective of attributing a deployment site's success to its own features and the features of its environment. Therefore, the formal models of how ATMs produce business value contain variables representing two different levels, the RSC and the individual ATM within the RSC.

The overall success of a deployment strategy is measured by aggregating the success measures of each ATM within each RSC.

Hypotheses. Our next step was to evaluate a series of hypotheses that attempt to examine the extent to which aspects of CAIT deployment qualitatively match the kinds of predictions that one would make about retail outlet deployment, given managerial choice variables, a fixed environment and a chosen set of success measures. The hypotheses are as follows:

Value Platform Hypothesis:

\section{Customer}

Hypothesis:

\section{Competitor}

Hypothesis:
ATMs with higher measures of value platform features will experience a larger number of transactions compared to ATMs with lower measures of value platform features.

ATMs deployed in environments with higher measures of customer features will experience a higher level of transactions compared to ATMs deployed in environments with lower measures of customer features.

ATMs deployed in environments with more competing ATMs will experience a smaller relative number of transactions compared to ATMs deployed in environments with fewer competing ATMs. 


\subsection{Data Collection}

Measuring ATM Success within RSCs. The hypotheses were tested using data from October 1987, a period that was considered to be typical of the bank's ATM activity. 1987 was the most recent period prior to the merger of two large regional networks in Pennsylvania which introduced radical changes to the deployment environment. US_ON_US and OTHERS_ON_US transactions were directly attributable to each of the bank's ATMs. To perform a value platform analysis for US_ON_OTHERS, however, transactions at competing ATMs had to be attributable to the bank's own ATMs, as well. For the purposes of demonstrating our method, RSCs were selected for evaluation where the concentration of ATMs was not too great. This tactic enabled us to reasonably identify the ATMs deployed by the bank and its competitors which were clearly drawing from the same demographic base for transaction production. Every RSC, on the other hand, had at least one of the bank's and one of its competitor's ATMs.

Managers at the research site assisted us in defining the RSCs and identifying interacting ATMs within them. Addresses of the bank's ATMs and addresses of the ATMs of competing banks to whom interchange fees were paid were available from the bank's Marketing Research Department. ATM street address locations were marked on detailed street maps provided by the bank for each RSC. The result was the definition of 31 RSCs, within which 64 of the bank's ATMs were placed. Competitors' ATMs numbered in the hundreds. When more than one of the bank's ATMs was located within an RSC, it was clear that they interacted with one another to a certain extent. For this reason, the number of competing banks' ATMs and measures of the number of customers within the RSC were allocated equally to each of the bank's ATMs.

Value Platform Features. Features were limited to those that were in effect during the period being studied and those for which the feature's measure showed variation. Since the bank had not charged fees to their customers for ATM transactions during the period, price could not be included as a value platform feature. Nor could availability be included as a value platform feature since almost all 
ATM sites were available on a 24 hour basis. The bank's records for each ATM indicated its functionality and location type. The managers in charge of retail facilities development rated all of the ATMs studied on each of the value platform characteristics in terms of a six-point scale.

Environmental Features. Measures of environmental features were available in the Branch Directory and Summary of Deposits [7] and were mapped to the clusters. The number of competing ATMs could be counted directly from the RSC maps.

Transaction Data. The bank maintained monthly US_ON_US and OTHERS_ON_US transaction data for each of its ATMs. A monthly US_ON_OTHERS report, which listed competing ATMs in descending order of the number of US_ON_OTHERS transactions generated, was also made available by the MAC network (then owned and operated by Core States Financial of Philadelphia, Pennsylvania) as part of its normal reporting services. This data was also mapped to the competing ATMs in each RSC.

\section{CUSTOMER SERVICE AND INTERCHANGE MODELS: BASELINE YEAR ANALYSIS}

This section reports on the results of preliminary correlation analysis conducted on the variables representing the major elements of the CAIT model. It also discusses the results of several regression analyses conducted for the transaction generation models, as well as their implications for the hypotheses that we proposed.

\subsection{Correlation Analysis}

To begin the evaluation of the customer service and interchange models, correlations were computed between each pair of variables (sample size $=64$ ). This analysis had the following goals:

(1) determining whether success measures were independent, and,

(2) identifying features that tended to be associated with one another.

Business Value Measures. Figure 3 presents the correlations among the three transaction types. Correlations between US_ON_US transaction production, and 
OTHERS_ON_US and US_ON_OTHERS transaction production are very low and insignificant. The correlation between OTHERS_ON_US and US_ON_OTHERS is much higher $(a=.42, p=.001)$. This result suggests that customers select ATMs based upon the type of transaction they wish to perform. When customers need to make deposits and transfers, they seek out the full function ATMs of their own bank, regardless of how many cash dispensing ATMs are nearby. Full function machines, therefore, appear to be primarily in competition with one another. When seeking quick cash, however, customers are not likely to discriminate between the ATMs of their own bank and those of another, rather, they simply seek the most convenient ATM. The bank's cash dispensing ATMs, therefore, are not only in competition with one another, but also in competition with the ATMs of all competing banks. This result supports the policy suggested by the bank's ATM managers of viewing most ATMs as being either primarily for customer service or primarily for interchange.

Figure 3. Correlations Among Success Measures

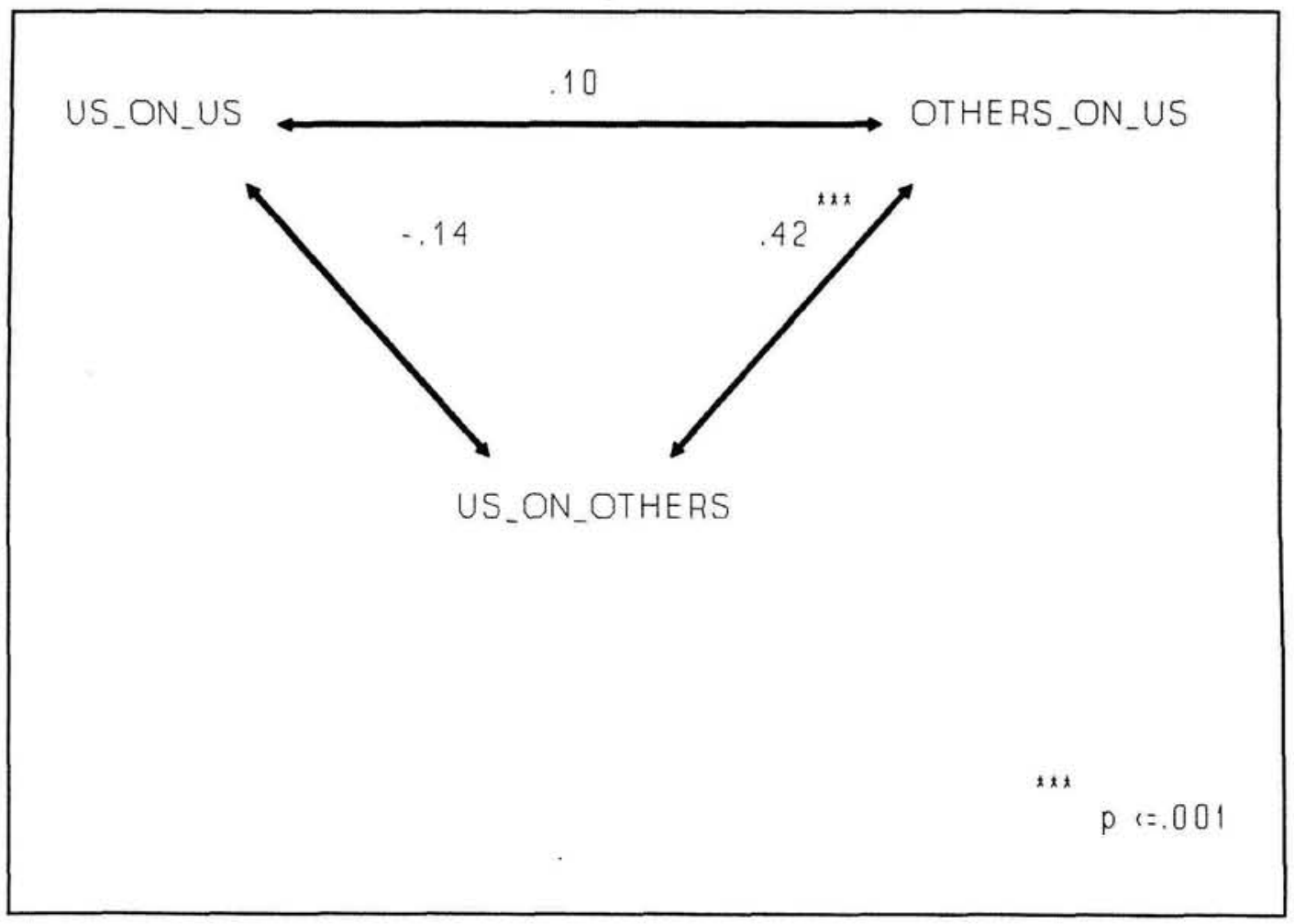

Measures of Environmental Features. Figure 4 presents the significant pair- 
wise correlations between environmental features. Competing banks' deposits had a tended to be associated with higher income environments $(a=.42, p=.001)$ and that higher income environments tend to be associated with higher numbers of surrounding ATMs $(\alpha=.45, p=.001)$. Senior managers whom we interviewed said there was a general perception of the bank in some of its markets as a "blue collar bank," but they were not aware of any explicit policy to target lower income customers. The high degree of association between the presence of competing banks' deposits and the presence of competing ATMs in clusters $(a=.65, p=.001)$ is not surprising since banks tend to deploy ATMs in or near their branches.

\section{Figure 4. Correlations Among Environmental Features}

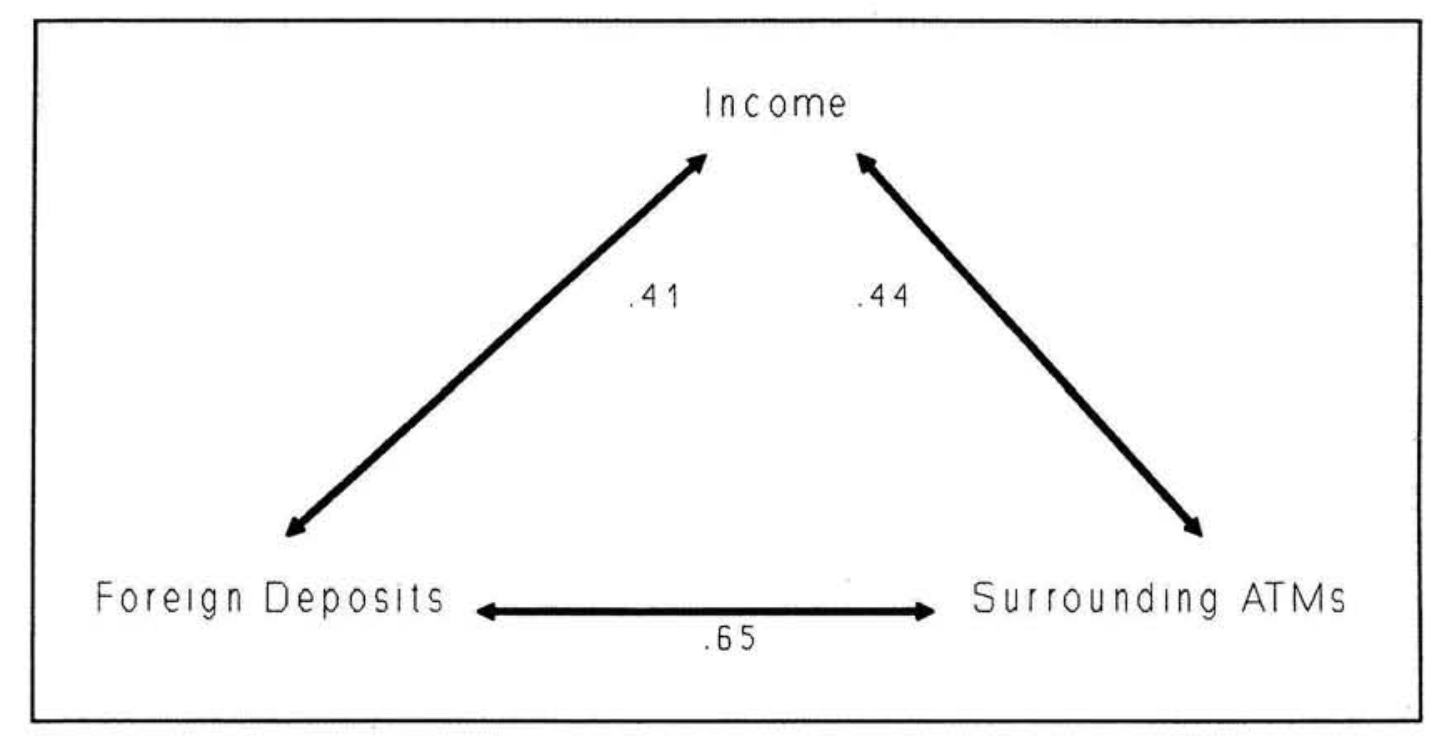

Value Platform Features. Figure 5 presents the significant pair-wise correlations between value platform variables. As expected, the two primary descriptors of the bank's ATMs, type and location, show moderately high correlations with each other and with a number of other value platform features that measure attractiveness.

These correlations reflect the bank's two ATM deployment objectives -customer service and interchange -- and indicate that a different value platform is typical of each. Full function ATMs tend to be deployed at branch locations where there is more surrounding auto traffic and where "drive-up" banking is possible. To 
attract interchange, cash dispensing ATMs tend to be deployed at non-branch Figure 5. Correlations Among Value Platform Features (Two-Tailed Significance $>$.05)

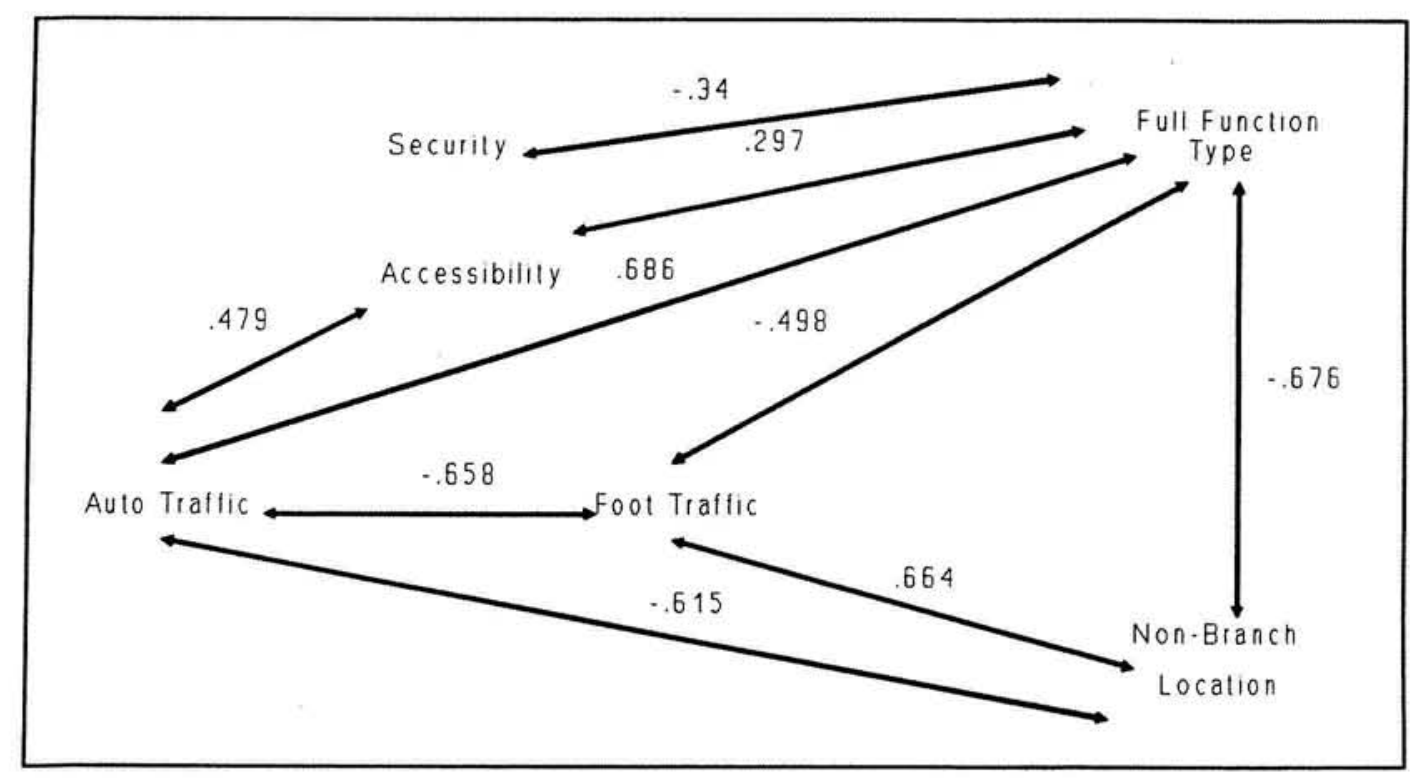

locations with high surrounding pedestrian traffic. ATMs considered to be highly accessible are highly visible as well.

The results of the correlation analysis were used to trim the formal model to avoid collinearity problems that could lead to unstable results. For example, location was dropped from the formal model after the correlation analysis and when discussions with management indicated that full function, drive-up ATMs were so likely to be at branch locations that location was simply a redundant measure of the same construct. Visibility was also dropped because after providing ratings of the various sites and being presented with the correlation results, managers felt that visibility was an aspect of accessibility and, therefore, was a measure of the same construct.

\subsection{Econometric Analysis Approach}

To evaluate the hypotheses, regression models containing environmental and value platform variables appropriate to each model were run. Variable inflation factors did not indicate strong correlations between any independent variable and the remaining set of independent variables. (Variable inflation factors are used to detect 
multi-collinearity and are given by $1 /\left(1 / R_{i}^{2}\right)$, where $R_{i}^{2}$ is the $R^{2}$ from regressing the ith independent variable on all other independent variables [18].

Simple linear regression models were used rather than multiplicative or higher order models. Management did not believe that environmental and value platform features interacted multiplicatively -- that extreme values of environmental or value platform features would have a highly leveraged impact on success measures or on the impact of other features on success measures. Although there were physical limits on the number of transactions one ATM could perform, these limits were only reached by a few ATMs during peak hours. For both these reasons, therefore, management believed that increases in features would generate proportional increases in transactions, making linear regression models an appropriate choice. The regression models used to estimate US_ON_US, OTHERS_ON_US and US_ON_OTHERS transactions are shown in Table 1.

The goals of the regression analysis were to:

(1) evaluate the hypotheses generated from the transaction generation models;

(2) identify the value platform and environmental features that are the best predictors of each transaction type;

(3) indicate to management value platform strategies that will enhance the business value of their ATMs.

Table 2 compares the full results of the analysis for the three models.

US_ON_US transactions. Of the value platform features, only the result for auto traffic provides evidence for rejecting the value platform null hypothesis $\left(\beta_{\text {AUTO_TRAF }}=974, p .=.001\right)$, indicating that this value platform feature is key for US_ON_US deployment.

The deployment environment conducive to US_ON_US transactions is characterized by small families $\left(\boldsymbol{\beta}_{\mathrm{FAM}} \mathrm{FIIZE}_{\mathrm{S}}=-2486, \mathrm{p}=.02\right)$, high income $\left(\boldsymbol{\beta}_{\mathrm{INC}}=.06\right.$, $\mathrm{p}=.04)$, and few competing ATMs $\left(\boldsymbol{\beta}_{\text {COMP_ATMS }}=-355, p=.02\right)$. The deposit base in the RSC has a positive coefficient but is not highly significant $\left(\beta_{\text {MER_DEP }}=.02, p=.19\right)$. The results, all in the expected direction, provide evidence for rejecting the null customer 
Table 1. Regression Model for the Three Transaction Types

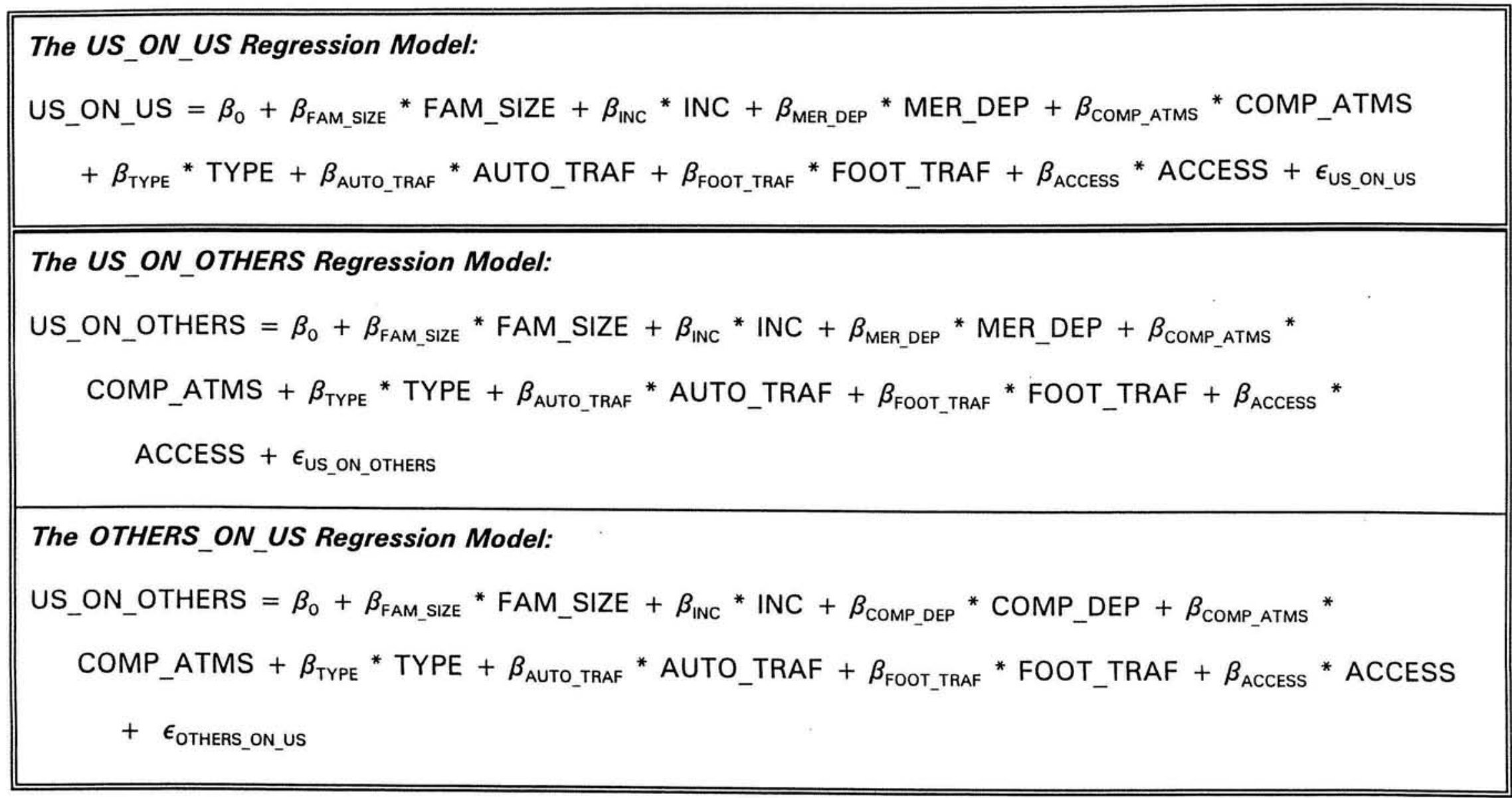


Table 2. Results of the Regression Analysis for the Three Models

\begin{tabular}{|c|c|c|c|c|c|c|}
\hline \multirow{2}{*}{$\begin{array}{l}\text { ESTIMATED MODEL } \\
\text { PARAMETERS }\end{array}$} & \multicolumn{2}{|c|}{ US_ON_US } & \multicolumn{2}{|c|}{ OTHERS_ON_US } & \multicolumn{2}{|c|}{ US_ON_OTHERS } \\
\hline & Coef. & t-stat. & Coef. & t-stat. & Coef. & t-stat. \\
\hline$\beta_{0}$ & 4629 & .13 & -299 & .91 & -1984 & .11 \\
\hline$\beta_{\text {FAM SIZE }}$ & -2486 & $.02 *$ & -1357 & .13 & 94 & $.03 *$ \\
\hline$\beta_{\text {INC }}$ & .06 & $.04 *$ & .07 & $.004 * * *$ & -.01 & .22 \\
\hline$\beta_{\text {MER DEP }}$ & .01 & $.19^{*}$ & ----- & ----- & .002 & .49 \\
\hline$\beta_{\text {COMP DEP }}$ & ----- & ----- & -.01 & .15 & ----- & ------ \\
\hline$\beta_{\text {COMP ATMS }}$ & -355 & $.02 *$ & 575 & $.001 * * *$ & 497 & $.001^{* * *}$ \\
\hline$\beta_{\mathrm{TYPE}}$ & 1465 & .09 & -757 & .303 & 158 & .64 \\
\hline$\beta_{\text {AUTO TRAF }}$ & 974 & $.001^{* * *}$ & 587 & $.02 *$ & 261 & $.02 *$ \\
\hline$\beta_{\text {FOOT_TRAF }}$ & 489 & .04 & 703 & $.001 * * *$ & 260 & $.007^{*}$ \\
\hline$\beta_{\text {ACCESS }}$ & -124 & .77 & 503 & .15 & -227 & .17 \\
\hline Adjusted $R^{2}$ & \multicolumn{2}{|c|}{.51} & \multicolumn{2}{|c|}{.44} & \multicolumn{2}{|c|}{.57} \\
\hline
\end{tabular}

Note: The asterisks beside the t-statistics indicate three levels of significance as follows --
${ }^{*} p<=.05$
${ }^{* *} p<=.01$
$\star \star \star p<=.001$ 
and competitor hypotheses for US_ON_US transaction generation. The adjusted $\mathrm{R}^{2}$ for the entire model is .514 , which provides validation for the CAIT deployment model concepts in a value platform analysis for the generation of US_ON_US transactions.

OTHERS_ON_US transactions. Significant positive coefficients for both surrounding auto traffic $\left(\beta_{\text {AUTO_TRAF }}=587, p=.02\right)$ and surrounding foot traffic $\left(\boldsymbol{\beta}_{\text {FOOT_TRAF }}=703, p=.001\right)$ indicate that both these features are important in designing an OTHERS_ON_US value platform. Surrounding ATMs have a significant positive coefficient $\left(\boldsymbol{\beta}_{\text {COMP_ATMS }}=575, p=.001\right)$. Interviews with retail facilities managers indicated that high interchange transactions tend to take place in busy high traffic areas such as intersections and shopping malls. Managers believed that these areas also attract competing ATMs, and that market saturation had not yet occurred in most places.

Appropriate environments for OTHERS_ON_US transaction production are again characterized by high income $\left(\boldsymbol{\beta}_{\mathrm{INC}}=.07, \mathrm{p}=.01\right)$ and, somewhat less significantly, by small families $\left(\beta_{\text {FAM_SIZE }}=-1357, p=.13\right)$. The competing banks' deposit base has a marginally significant negative coefficient $\left(\beta_{\text {COMP_DEP }}=-.01, p=.15\right)$, which is contrary to the expectations of the CAIT model. The negative coefficient for competing deposits may indicate that competing banks' customers, rather than using the other banks' ATMs near where their deposits are located, are more likely to use the bank's ATMs when there are none of their own bank's branches and ATMs nearby. Therefore, there is evidence for rejecting the customer null hypotheses with respect to family size and income, but not with respect to the deposit base. The adjusted $\mathrm{R}^{2}$ squared of the OTHERS_ON_US model is .437 , slightly lower than for the US_ON_US scenario.

US_ON_OTHERS transactions. The value platform features, auto traffic $\left(\beta_{\text {AUTO_TRAF }}=261, p=.02\right)$ and foot traffic $\left(\beta_{\text {FOOT_TRAF }}=260, p=.007\right)$ both have positive, significant impacts, although with smaller coefficient values than was the case with US_ON_US or OTHERS_ON_US transaction generation. This again suggests that interchange transactions take place in high traffic areas. The coefficient for surrounding ATMs is positive and highly significant $\left(\boldsymbol{\beta}_{\text {COMP_ATMS }}=497, p=.001\right)$, 
providing evidence for rejecting the null hypothesis regarding competing ATMs, and reinforcing the CAIT model concept that surrounding ATMs draw off the bank's customers. These findings suggest that the favorable impacts of enhanced auto and foot traffic in interchange ATM value platforms can be dampened by the presence of many competing ATMs.

For US_ON_OTHERS transactions family size has an unexpected positive coefficient $\left(\boldsymbol{\beta}_{\text {FAM_SIZE }}=944, p=.03\right)$. Examination of the scatter plot of family size and US_ON_OTHERS transactions indicates that the results appear to be influenced by three outliers in a subset of the region that was primarily agricultural. With these observations removed, the coefficient becomes insignificant. The adjusted $R^{2}$ of this model was .568 .

General Results. The results of the regression analysis support the CAIT model concept that environments with higher per capita income and smaller families are more conducive to the success of the bank's ATMs at generating transactions. The negative impact of surrounding ATMs on the success of ATMs in generating transactions and resisting the loss of transactions to surrounding competing ATMs was supported by the US_ON_US and US_ON_OTHERS models. However, the results of the OTHERS_ON_US model did not support the negative impact suggested by the CAIT model, most likely because these transactions tend to take place in high traffic areas where competing banks are likely to deploy their ATMs as well.

Of the value platform features, surrounding auto traffic and foot traffic emerge as being supportive of the bank's ATM transaction generation. Their positive coefficients in the US_ON_OTHERS model again most likely reflect the tendency of competing banks to deploy their ATMs in high traffic areas. No value platform features that we were able to investigate appear to have a significant impact on preventing transactions at competing ATMs.

\subsection{Managerial Perspective: The Emergence of Two Separate Deployment Scenarios}

Results generated at all stages of the analysis, including

(1) the high correlation between OTHERS_ON_US and US_ON_OTHERS 
transactions,

(2) the correlations between value platform variables,

(3) the positive coefficient for surrounding ATMs for OTHERS_ON_US transactions, and

(4) the positive coefficients for auto traffic and foot traffic for US_ON_OTHERS transactions

provide evidence that ATMs deployed for interchange face a different competitive scenario than machines deployed for customer service. Since ATMs are usually deployed with either customer service or interchange fees in mind, ATM managers should draw insight from the results of the ATM models that best represent the goal of the particular deployment.

For customer service deployments, the bank should target high income, small family environments with few competing ATMs and focus its value platform on easy auto access.

For interchange deployments, high income and small family size in the surrounding environment play a less important role. Key to success here is a value platform location that has sufficient auto and foot traffic at the immediate ATM site. Managers also need to be aware of the growing potential for market saturation as competing banks flood promising publicly accessible sites with cash dispensers, negating the impact of high customer traffic levels. Long-term interchange success, therefore, may depend on aggressively seeking unconquered territory -- high traffic sites such as airports and train stations where no competing ATMs are located.

\section{Contributions, Limitations and Further Applications}

To conclude this paper, we discuss the primary contributions of our study and consider the limitations of the results. Finally, a general approach to applying value platform analysis is developed.

\subsection{Contributions and Limitations}

The value platform analysis perspective that we developed and applied in this 
study provides insights from marketing theory into the problem of evaluating an important and emerging subset of information technology. The perspective contributes insights about the key issues in CAIT deployment and their impact on business value. The empirical portion of the study demonstrates how electronic banking services can be conceptualized as a CAIT, and evaluated in terms of how managerially controllable value platform features interact with managerially uncontrollable features of the environment, impacting system success.

For ATM deployment managers, two main insights were obtained:

(1) Based on our results, it makes sense to conceptualize their bank's ATM deployment plans in terms of two different settings -- customer service and interchange. Different deployment strategies are appropriate for each scenario.

(2) Among the environmental features driving deployment success in these two scenarios, customer base income and family size were shown to favorably impact both. However, managers need to bear in mind that despite these similarities, deployment of ATMs in the two scenarios will require attention to different value platform design details.

With the insights provided by these models, ATM deployment managers are in a better position to anticipate the impacts of changes brought about by the merger of regional networks. The model suggests, for example, that an increase in the number of surrounding ATMs is likely to have major impacts on the number of transactions a bank's customers conduct at competing machines, whereas increases in the customer base are not likely to alter the performance of individual ATM sites.

As with any research program that is limited to one firm, we caution the reader to recognize that the results obtained from our data set have not been validated externally. On the other hand, we have every reason to believe that the deployment scenarios that we characterized for Meridian Bancorp are probably common within the industry, and that the dynamics of electronic banking service competition and site performance that were observed in southeastern Pennsylvania are replicated in many other areas around the U.S. 


\subsection{Applying Value Platform Analysis}

The value platform analysis technique can be used by a CAIT deployment manager either: 1) ex ante -- to determine if a potential deployment scenario provides an appropriate match between environmental and value platform features, or 2) ex post -- to fine tune an existing deployment strategy.

Ex ante Evaluation. Prior to the deployment of a CAIT, managers who oversee CAIT deployment can use value platform analysis to evaluate ex ante potential value platforms and deployment environments to determine whether a sufficient customer base exists, what the qualities of the technical platform should be, whether competing technologies are likely to siphon off some of the customer base, and whether success is likely to result.

Application of value platform analysis could have provided insight to the managers of Chemical Bank's failed home-banking system, Pronto [15]. Chemical Bank did not fully consider how their value platform, which required that users own a PC, further limited their already small potential customer base of users. Chemical further failed to consider that ATMs, introduced at about the same time, offered customers many of the same services.

As a conceptual tool for evaluating new deployment scenarios, value platform analysis presents important issues that need to be addressed before a major investment takes place. Value platform analysis also suggests empirical referents for measuring whether conducive deployment environments exist. And when heterogeneous deployment environments exist, value platform analysis can help managers decide which environments are most likely to have a favorable impact on a CAIT's ability to generate value for a firm.

Ex post Evaluation. The main results of the study show the applicability of our value platform analysis perspective and CAIT modelling as an ex post evaluative tool. With a base of CAITs already deployed, value platform analysis can be used to provide an empirical evaluation of the current deployment strategy. To apply value platform analysis, the deployment scenario must be characterized in terms of: 
Environmental Evaluation.

(1) What characteristics of my customers make it likely that they will use the CAIT?

(2) What alternatives do my customers have to using the CAIT sites my organization provides?

(3) What empirical referents provide a good proxy for these features?

(4) Do these features vary among the deployment environments?

Value Platform Evaluation.

(1) What alternative CAIT features can I offer to my customers?

(2) What is the likely impact of these features on the CAITs ability to provide business value to my firm?

(3) How can I measure these features?

From this analysis, formal models can be developed to describe the interaction of the CAIT value platform and deployment environment on its success, and data can be gathered to measure key features. Quantitative models for analysis of the impact of key features can be chosen depending on the nature of the relationship between the features and business value measures. Elsewhere, data envelopment analysis has been applied to evaluate CAIT production and to create additional managerial insights [1].

The results of the empirical analysis can indicate to managers:

* whether environmental or value platform features play a dominant role in the CAIT's ability to provide business value;

* which immediately feasible changes in the value platform will have positive impact on business value;

* which environmental features are most conducive to the generation of business value, suggesting eventually feasible actions for locating new CAIT sites.

Armed with such insight, managers can fine tune their present CAIT 
deployment strategy and plan more successful strategies in the future. 


\section{REFERENCES}

[1] Banker, R. D., Kauffman, R.J., \& Lally L. Gauging the quality of managerial decisions regarding information technology deployment. Proceedings of the Twenty-Fourth Hawaii International Conference on Systems Sciences, 1991, 4, 276-287.

[2] Banker, R. D., Kauffman, R.J., \& Mahmood, M.A. Strategic information technology management: Perspectives on organization growth and competitive advantage. Middletown, PA: Idea Group Publishing, 1993.

[3] Churchill, G. A. Marketing research: Methodological foundations. Hillsdale, IL: The Dryden Press, 1983.

[4] Clemons, E., \& Row, M. McKesson Drug Company: A case study of economost -- A strategic information system. Journal of Management Information Systems, 1988, 5(1), 36-50.

[5] Clemons, E., \& Weber, B.W. Making the information technology investment decision: A principled approach. Proceedings of the Twenty-Third Hawaii International Conference on Systems Sciences, 1990, 3, 235-243.

[6] Davidson, W.R., Sweeney, D.J. \& Stampfl, R.W. Retailing management, New York: John Wiley and Sons, 1984.

[7] Decision Science Research, Inc. Branch directory and summary of deposits. Blue Bell, PA, 1987 and 1988.

[8] Ferber, R. Variation in retail sales between cities. Journal of Marketing, 1958, 22(3), 295-303.

[9] Ghosh, A., \& McLafferty S.L. Location strategies for retail and service firms. Lexington, MA: Lexington Books, 1987.

[10] Glaser, P. F. Using technology for competitive advantage: The ATM experience at Citicorp. from Managing innovation: Cases from the service industries. Guile, B.R. \& Quinn, J.B. eds., Washington, DC: National Academy Press, 1988.

[11] Guenther, R. Chemical banking, AT\&T to scrap home banking service. Wall Street Journal, December 5, 1988, 21.

[12] Hammer, M., \& Mangurian, G. The changing value of communications technology. Sloan Management Review, 1987, 28(2), 65-71. 
[13] Ingene, C.A. Structural determinants of retail potential. Journal of Retailing, $1984,60(1), 37-64$.

[14] Johnston, H. R., \& Vitale M.R. Creating competitive advantage with interorganizational information systems. MIS Quarterly, 1988, 12(2), 153-165.

[15] Kauffman, R. J., \& Lally, L. Customer access information technology deployment evaluation. Proceedings of the Twenty-First Annual Meeting of the Northeast Decision Sciences Institute, 1992, 271-275.

[16] Kauffman, R. J., \& Weill, P. An evaluative framework for research on the performance effects of information technology investment. Proceedings of the Tenth International Conference on Information Systems, 1988, 377-388.

[17] Keen, P. Competing in time. Cambridge, MA: Harper and Row, 1986.

[18] Kennedy, P. A guide to econometrics -- second edition, Cambridge, MA: MIT Press, 1985.

[19] Kotler, P. Marketing management: Analysis, planning and control, Englewood Cliffs, NJ: Prentice Hall, 1988.

[20] Kouzelis, A. On the determinants of ATM performance. European Journal of Operations Research, 1987, 30(2), 89-94.

[21] Lipis, A., Marschall, T., \& Linker, J.H. Electronic banking. New York, NY: John Wiley, Inc., 1985.

[22] Liu, B.C. Determinants of retail sales in large metropolitan areas; 1954 and 1963. Journal of the American Statistical Association, 1970, 65(1), 1460-1473.

[23] McAndrews, J. J., \& Kauffman, R,J. Network adoption and shared electronic banking network adoption. Working Paper, Department of Economic Research, Federal Reserve Bank of Philadelphia, 1993.

[24] McCarthy, J. Basic marketing, a managerial approach, 3rd edition. Homewood, IL: Irwin, 1981.

[25] McFarlan, F. W. Information technology changes the way you compete. Harvard Business Review, May-June, 1984, 98-103.

[26] Petre, P. How to keep customers happy captives. Fortune, September 2, 1985, 42-46. 
[27] Rachman, D. Retail strategy and structure, Englewood Cliffs, NJ: Prentice-Hall, 1975.

[28] Reich, B.H., \& Benbasat, I. An empirical investigation of the factors influencing the success of customer-oriented strategic systems. Information Systems Research, 1990, 1(3), 325-347.

[29] Roche, E. Telecommunications and business strategy, Niles, IL: The Dryden Press, 1991.

[30] Steiner, T. D., \& Teixeira, D. Information technology in banking. New York, NY: Dow Jones-Irwin, 1989.

[31] Thompson, J. M., \& K. C. Mead. Boost your market power with information technology. Indications, 1988, 5(2). 1-4.

[32] Tigert, D. J. Pushing the hot buttons for a successful retailing strategy. Patronage Behavior and Retail Management. Darden, R. \& Lusch, R.F., eds. New York: North-Holland, 1983 45-57.

[33] Roth, A. V., \& Van der Velde, M. The future of retail banking delivery systems. Rolling Meadows, IL: Bank Administration Institute, 1988.

[34] Vepsalainen, A., \& Apte, U. The impact of information technology on financial services delivery. Working paper, \#87-12-01, Department of Decision Sciences, The Wharton School, University of Pennsylvania, PA, Pennsylvania, 1987. 